\title{
Performance Evaluation of SENTIFIT 270 and FOB Gold Reagent for Detecting Fecal Occult Blood
}

\author{
Da Young Kang ${ }^{1,2}$, Dokyun Kim, Keonhan Kim¹, In-Ho Jang², Seok Hoon Jeong ${ }^{1}$ \\ ${ }^{1}$ Department of Laboratory Medicine and Research Institute of Bacterial Resistance, \\ Yonsei University College of Medicine, Seoul, \\ ${ }^{2}$ Department of Clinical Pathology, Sangji University College of Health Science, Wonju, Korea
}

Background: Fecal occult blood tests have been widely used to screen for colorectal cancer. SENTiFIT 270 (Sentinel diagnostics, Italy) is a fecal occult blood test with an immunochemical method that utilizes FOB Gold reagents. We evaluated the performance of SENTiFIT 270 using the FOB Gold reagent. In addition, FOB Gold was evaluated with the HITACHI 7180 (Hitachi Ltd., Japan).

Methods: The precision and linearity of the SENTiFIT 270 was evaluated in accordance with applicable Clinical and Laboratory Standard Institute guidelines. The comparison study between SENTiFIT 270-FOB Gold and the OC-Sensor (Eiken chemical Co., Japan) was performed using stool specimens.

Results: In the precision evaluation, the total precision of SENTiFIT 270-FOB Gold was $4.94 \%$ and $2.54 \%$ at high and low concentrations, respectively.
The HITACHI 7180-FOB Gold had excellent precision of $4.60 \%$ and $2.09 \%$ at high and low concentrations, respectively. Linearity was also excellent for the SENTIFIT 270-FOB Gold and HITACHI 7180-FOB Gold at 0.9987 and 0.9986 , respectively. The SENTITIF $270-F O B$ Gold showed excellent agreement with a kappa value of 0.830 and a concordance rate of 93.6\%. The HITACHI 7180-FOB Gold showed high agreement with a kappa value of 0.832 and a concordance rate of $93.9 \%$.

Conclusion: The SENTiFIT 270-FOB Gold showed excellent performance in accuracy, linearity, and comparative inspection ability. (Ann Clin Microbiol 2019; 22:29-34)

Key Words: Colon cancer, Linearity, Occult blood, Precision, SENTiFIT 270-FOB Gold

\section{INTRODUCTION}

대장암은 한국에서 갑상선암, 위암에 이어 세 번째로 흔한 암이다[1]. 2000년대 초반에는 10만명당 27.9명으로 그 빈도가 낮았으나, 근래에 서구화된 식생활, 운동 부족, 정제된 음식의 과다 섭취, 과도한 스트레스, 과음과 흡연 등의 생활 습관으로 인해 대장암의 발생 빈도가 증가하여, 2008년에는 10 만명당 208.5명에서, 2015년에는 10 만명당 398.5명으로 크게 증가하였 다 [1,2]. 대장암은 다른 종양보다는 비교적 진행이 느리고 치료 방법도 효과적으로 잘 정립되어 있다. 대장암 환자의 생존율은 발견 시의 병기가 가장 중요한 것으로 알려져 있다. 대장암의 발견 시 원발부위에 국한된 종양으로 장기의 경계선 너머로 퍼 지지 않은 경우에는 5년 생존율이 $90 \%$ 이상, 종양이 원래 기원 한 장기의 범위를 벗어나 주위의 장기나 조직에 침범, 전이된
경우에는 약 $70 \%$, 원거리 전이가 있는 경우는 약 $10 \%$ 인 것으 로 알려져 있으므로 대장암의 사망률을 낮추기 위하여 전암성 병변을 조기에 발견하고 진단하는 것이 중요하다[3].

국내 국가 암조기검진 사업에는 대장암의 조기 진단을 위해 대변잠혈검사(Fecal occult blood test)와 대장내시경이 포함되 어 있다[4]. 대변잠혈검사는 50 세 이상의 인구집단에서 매년, 대장내시경은 10 년마다 시행하는 것을 권장하고 있다. 대장내 시경 검사는 정확도가 높고 용종이 발견되면 바로 제거가 가능 한 장점이 있으나, 선별 검사로 하기에는 검사 시 통증과 불편 감 때문에 환자의 순응도가 떨어지고 천공 및 출혈 등의 합병 증이 발생할 수 있다. 대변잠혈검사는 시행이 비교적 쉽고, 비 침습적이며, 비용이 저렴하여 대장암 조기진단을 하기 위한 일 차 선별 검사로 많이 이용되고 있으며, 그 임상적 효능이 입증 되었다[5,6].

Received 14 September, 2018, Revised 25 November, 2018, Accepted 26 November, 2018

Correspondence: Dokyun Kim, Department of Laboratory Medicine and Research Institute of Bacterial Resistance, Gangnam Severance Hospital, Yonsei University College of Medicine, 211 Eonju-ro, Gangnam-gu, Seoul 06273, Korea. (Tel) 82-2-2019-2776, (Fax) 82-2-2057-8926, (E-mail) kyunsky@yuhs.ac

(c) The Korean Society of Clinical Microbiology.

(ㅈ) This is an Open Access article distributed under the terms of the Creative Commons Attribution Non-Commercial License (http://creativecommons.org/licenses/by-nc/4.0) which permits unrestricted non-commercial use, distribution, and reproduction in any medium, provided the original work is properly cited. 
대변잠혈검사는 생화학적 방법과 면역화학적 검사방법이 소 개되어 있다. 생화학적인 방법인 Guaiac test는 식품에 의한 위 양성 등으로 인해 특이도가 낮다[7,8]. 면역화학적 방법은 사람 헤모글로빈에 특이한 항체를 이용하기 때문에 혈액검출에 대 한 특이도가 높고 출혈부위에 대한 선별이 가능하여 민감도 또 한 높아 최근 검사실에서는 후자의 검사방법을 이용하는 대변 잠혈검사가 보편화되고 있다. 2016년 국내 외부정도관리 결과 에 따르면, 대변잠혈검사 장비 중 OC-Sensor (Eiken chemical Co., Tokyo, Japan)를 가장 널리 사용하며, NS-prime (Alfresa pharma Co., Osaka, Japan), HM-JACKarc (Kyowa Ltd., Tokyo, Japan)을 다음으로 많이 사용하였다[9].

SENTiFIT 270 (Sentinel diagnostics, Milano, Italy)은 최근에 소개된 전용장비로 FOB Gold 시약을 이용하여 면역화학적 방 법을 통해 대변잠혈검사를 시행하며, 그 검사능에 대한 평가가 부족하다[10]. 따라서, 본 연구자들은 대장암의 일차 선별 검사 로 널리 이용되는 대변잠혈검사 장비인 SENTiFIT 270 (Sentinel diagnostics)과 그 시약인 FOB Gold의 성능을 평가하 였으며, 추가적으로 검사실 범용장비 중 하나인 HITACHI 7180 (Hitachi Ltd., Tokyo, Japan)을 이용한 FOB Gold 시약의 분석능을 평가하였다.

\section{MATERIALS AND METHODS}

\section{1. 측정방법}

FOB Gold 시약을 사용하여, 전용장비인 SENTiFIT 270 (Sentinel diagnostics)과 HITACHI 7180 (Hitachi Ltd.)을 이용하 여 대변잠혈검사를 시행하였다. 채변용기에 채취된 변을 멸균 면봉을 이용하여 $1.7 \mathrm{~mL}$ 의 헤모글로빈 안정화 버퍼가 포함되 어 있는 전용용기에 옮긴 후 기기에 장착하였다. 이후, 사람 헤 모글로빈에 대한 다클론성 항체가 흡착된 라텍스 입자 현탁액 이 첨가되고, 응집반응을 흡광도로 측정하였다. $100 \mathrm{ng} / \mathrm{mL}$ 미 만을 음성으로, $100 \mathrm{ng} / \mathrm{mL}$ 이상이면 양성으로 판단하였다.

\section{2. 정밀도(precision) 평가}

정밀도 평가는 CLSI EP15-A [11]에 따라 제조사에서 제공하 는 고농도 $(304 \mathrm{ng} / \mathrm{mL})$ 및 저농도 $(82 \mathrm{ng} / \mathrm{mL})$ 의 2 가지 정도관리 물질을 이용하여 총 20 일간 하루에 2 회, 매 검사마다 2 회씩 반 복 측정하여 시행하였으며, 하루에 시행되는 2 회의 검사는 최 소한 2 시간 이상의 간격을 두고 측정하였다.

\section{3. 직선성(linearity) 평가}

직선성 평가는 CLSI EP6-A2 [12]에 준하여 총 5가지 농도의 검체, 즉 고농도 검체 및 저농도 검체, 그리고 이를 각각 $1: 3,2: 2$, $3: 1$ 로 혼합한 검체를 이용하여 2 회 반복 측정하여 평가하였다. SENTiFIT 270-FOB Gold는 저농도 $(0.5 \mathrm{ng} / \mathrm{mL})$, 고농도(768.0 $\mathrm{ng} / \mathrm{mL}$ )의 검체와 이들을 혼합한 중간농도 3 개를 포함하여 총 5 개 농도의 검체로 평가하였다. HITACHI $7180-\mathrm{FOB}$ Gold의 경우 저농도 $(0.0 \mathrm{ng} / \mathrm{mL})$, 고농도 $(1,132.5 \mathrm{ng} / \mathrm{mL})$ 검체와 이들을 혼합한 중간농도 3 개를 포함하여 직선성을 평가하여 SENTiFIT 270-FOB Gold에서 보다 높은 농도까지 직선성을 검증하였다.

\section{4. 검체 간 교차오염률(canyover) 평가}

SENTiFIT 270 (Sentinel diagnostics)과 HITACHI 7180 (Hitachi Ltd.)을 각각 1 개의 고농도 및 저농도 검체를 4회씩 반 복 측정하였다 $(\mathrm{H} 1, \mathrm{H} 2, \mathrm{H} 3, \mathrm{H} 4, \mathrm{~L} 1, \mathrm{~L} 2, \mathrm{~L} 3, \mathrm{~L} 4)$. 검체 간 교차 오염률은 다음 식으로 구하였다.

$$
\begin{aligned}
& \% \text { carryover } \\
& =((\mathrm{L} 1-(\mathrm{L} 3+\mathrm{L} 4) / 2)) /((\mathrm{H} 3+\mathrm{H} 2) / 2-(\mathrm{L} 3+\mathrm{L} 4) / 2) \times 100
\end{aligned}
$$

\section{5. 일치도(method comparison) 평가}

상관성 평가는 CLSI EP9-A2 [13]에 준하여 시행되었다. 2017년 11월부터 2018년 3월까지 임상에서 대변잠혈검사가 의 뢰된 환자 362 명의 잔여 검체를 이용하였으며, 최소 50 개 이상 의 양성검체를 포함하도록 하였다. SENTiFIT 270-FOB Gold와 HITACHI 7180-FOB Gold를 이용한 측정값은 OC-Sensor (Eiken chemical Co.)의 결과와 비교하였다. 환자의 잔여 검체 사용에 대한 동의 면제는 임상연구에 대한 기관 검토위원회에 의해 승인되었다.

\section{6. 통계 분석}

정밀도 평가는 변이계수를 계산하여 제조사가 제시하는 기준 과 비교하였다. 직선성은 회귀분석을 통하여 회귀방정식 및 비 직선성\%를 구하여 평가하였다. 상관성은 제조사가 제시한 cut-off를 기준으로 양성/음성 결과를 비교하고 일치율을 구하였 다. 통계 분석은 Analyse-it for Microsoft Excel (Analyse-it Software Ltd., Leeds, UK)을 사용하여 시행하였다.

\section{RESULTS}

\section{1. 정밀도}

총 20 일간 저농도와 고농도 표준물질을 사용하여 측정한 FOB Gold 시약의 정밀도는 전용장비인 SENTiFIT 270 (Sentinel diagnostics)에서, 일괄검사 내(within-run), 일괄검사 간(between-run), 검사일 간(between-day) 변이계수가 저농도에 서 각각 $3.92 \%, 1.30 \%, 3.51 \%$ 였고, 고농도에서 각각 $1.88 \%$, $0.81 \%, 1.51 \%$ 였다. 또한, SENTiFIT-FOG Gold의 총 정밀도는 저농도과 고농도에서 각각 $4.94 \%, 2.54 \%$ 로 우수한 정밀도를 보였다. HITACHI 7180 (Hitachi Ltd.) 장비를 이용한 $\mathrm{FOB}$ 
Gold 시약의 일괄검사 내, 일괄검사 간, 검사일 간 변이계수는 저농도에서 각각 $3.75 \%, 2.50 \%, 1.85 \%$ 였으며, 고농도에서는 각각 $1.54 \%, 1.13 \%, 0.87 \%$ 였다. HITACHI $7180-\mathrm{FOB}$ Gold의 총 정밀도는 저농도과 고농도에서 각각 $4.60 \%, 2.09 \%$ 로 우수 한 정밀도를 보였다(Table 1).

\section{2. 직선성}

선형회귀분석 결과 결정계수는 SENTiFIT 270-FOB Gold 및 HITACHI 7180-FOB Gold에서 각각 0.9987, 0.9986이었다. 직 선성을 검증하였을 때도, 측정치를 가장 잘 설명하는 방정식은 1 차 함수 $(\mathrm{y}=1.002 \mathrm{x}+6.142$, SENTiFIT 270-FOB Gold; $\mathrm{y}=1.001 \mathrm{x}$ +11.769 , HITACHI 7180-FOB Gold)로 우수한 결과를 보여주 었다(Fig. 1).

Table 1. Precision for FOB Gold with SENTiFIT 270 and HITACHI 7180

\begin{tabular}{lccccc}
\hline \multirow{2}{*}{ Parameters } & \multicolumn{2}{c}{ SENTiFIT 270} & & \multicolumn{2}{c}{ HITACHI 7180} \\
\cline { 2 - 3 } \cline { 5 - 6 } & Low level & High level & & Low level & High level \\
\hline Mean & 83.15 & 298.10 & & 85.64 & 312 \\
Within run & & & & & \\
SD & 3.26 & 5.60 & & 3.22 & 4.79 \\
CV (\%) & 3.92 & 1.88 & & 3.75 & 1.54 \\
Between run & & & & & \\
SD & 1.08 & 2.40 & & 2.14 & 3.52 \\
CV (\%) & 1.30 & 0.81 & & 2.50 & 1.13 \\
Between day & & & & & \\
SD & 2.92 & 4.51 & & 1.59 & 2.71 \\
CV (\%) & 3.51 & 1.51 & & 1.85 & 0.87 \\
Total & & & & & \\
SD & 4.11 & 7.58 & & 3.94 & 6.53 \\
CV (\%) & 4.94 & 2.54 & & 4.60 & 2.09 \\
\hline
\end{tabular}

Abbreviations: $\mathrm{SD}$, standard deviation; $\mathrm{CV}$, coefficient of variation.

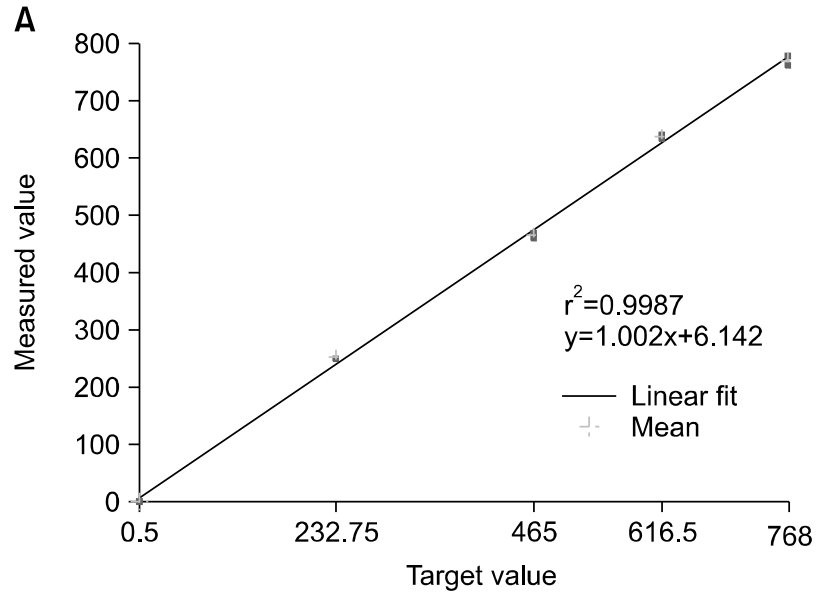

\section{3. 검체 간 교차오염률}

SENTiFIT 270 (Sentinel diagnostics)에서 하나의 동일한 고 농도의 검체를 4번 반복 측정한 값은 $780 \mathrm{ng} / \mathrm{mL}, 776 \mathrm{ng} / \mathrm{mL}$, $828 \mathrm{ng} / \mathrm{mL}, 795 \mathrm{ng} / \mathrm{mL}$ 로 평균 $\pm \mathrm{SD}$ 는 $794.8 \pm 23.6 \mathrm{ng} / \mathrm{mL}$ 였고, 저농도 검체를 4번 반복 측정한 값은 $48 \mathrm{ng} / \mathrm{mL}, 41 \mathrm{ng} / \mathrm{mL}, 50$ $\mathrm{ng} / \mathrm{mL}, 52 \mathrm{ng} / \mathrm{mL}$ 으로 평균 $\pm \mathrm{SD}$ 는 $47.8 \pm 4.8 \mathrm{ng} / \mathrm{mL}$ 였다. 검체 간 교차오염률은 $-0.4 \%$ 로 매우 낮았다.

HITACHI 7180 (Hitachi Ltd.)에서 고농도를 4번 반복 측정 한 값은 $1,796 \mathrm{ng} / \mathrm{mL}, 1,806 \mathrm{ng} / \mathrm{mL}, 1,797 \mathrm{ng} / \mathrm{mL}, 1,808 \mathrm{ng} / \mathrm{mL}$ 로 평균 $\pm \mathrm{SD}$ 는 $1,801.8 \pm 6.1 \mathrm{ng} / \mathrm{mL}$ 였고, 저농도를 4 번 반복 측 정한 값은 $41 \mathrm{ng} / \mathrm{mL}, 39 \mathrm{ng} / \mathrm{mL}, 27 \mathrm{ng} / \mathrm{mL}, 36 \mathrm{ng} / \mathrm{mL}$ 로 평균 $\pm \mathrm{SD}$ 는 $35.8 \pm 6.2 \mathrm{ng} / \mathrm{mL}$ 였다. 검체 간 교차오염률은 $0.5 \%$ 로 역 시 매우 낮았다.

\section{4. 일치도 평가}

SENTiFIT 270 (Sentinel diagnostics)과 HITACHI 7180 (Hitachi Ltd.)을 이용한 FOB Gold 시약의 경계치(cut-off)를 적 용한 양성/음성 결과를 OC-Sensor (Eiken chemical Co.)의 결과 와 비교하였다. SENTiFIT 270-FOB Gold의 경우 총 362개의 검체 중 OC-Sensor (Eiken chemical Co.)에서 양성으로 나온 검 체가 81개였으며, SENTiFIT 270-FOB Gold에서는 그 중 75개 (93.0\%)에서 양성을 보여주었다. OC-Sensor (Eiken chemical Co.)에서 음성으로 나온 검체는 281개였으며, SENTiFIT 270-FOB Gold에서는 그 중 264개(94.0\%)에서 음성의 결과가 나왔다. 따라서 총 일치율은 $93.6 \%$ 였으며, kappa 값은 0.830 으 로 우수한 일치도를 보여주었다. 범용장비인 HITACHI 7180 (Hitachi Ltd.)의 경우 총 362개의 검체 중 OC-Sensor (Eiken chemical Co.)에서 양성으로 나온 81개의 검체 중 75개(92.6\%) 에서 양성을 보였다. OC-Sensor (Eiken chemical Co.)에서 음성 으로 나온 281개 중 265개(94.3\%)에서 음성의 결과가 나왔다.

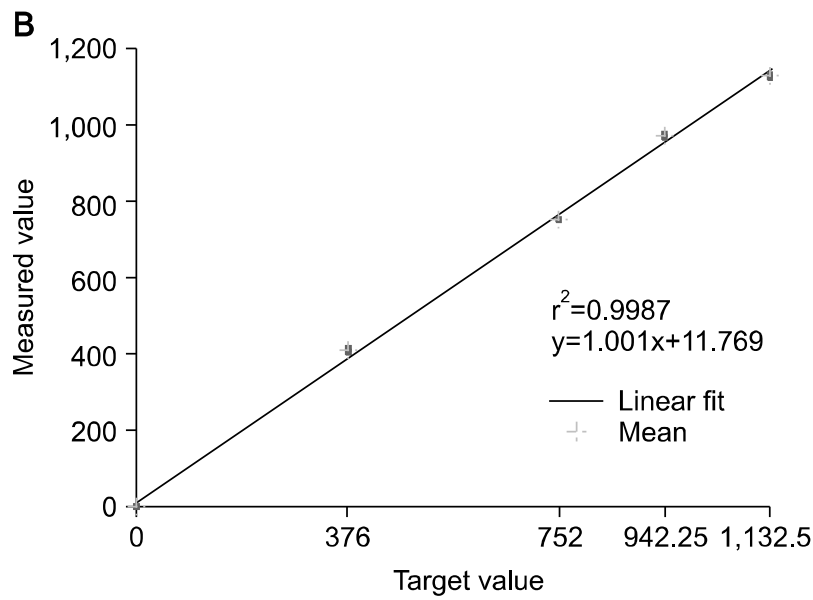

Fig. 1. Linearity of SENTiFIT 270-FOB Gold (A) and HITACHI 7180-FOB Gold (B). 
Table 2. Comparison of the results between FOB Gold with SENTiFIT 270 and HITACHI 7180, and OC-Sensor

\begin{tabular}{clrrr}
\hline \multirow{2}{*}{ Kits } & \multicolumn{1}{c}{ Results } & \multicolumn{2}{c}{ OC-Sensor } & kappa value (95\% CI) \\
\cline { 3 - 4 } & & Positive & Negative & $0.830(0.757-0.894)$ \\
\hline \multirow{2}{*}{ SENTiFIT 270-FOB Gold } & Positive & 75 & 17 & $0.832(0.765-0.900)$ \\
& Negative & 6 & 264 & 16 \\
\hline
\end{tabular}
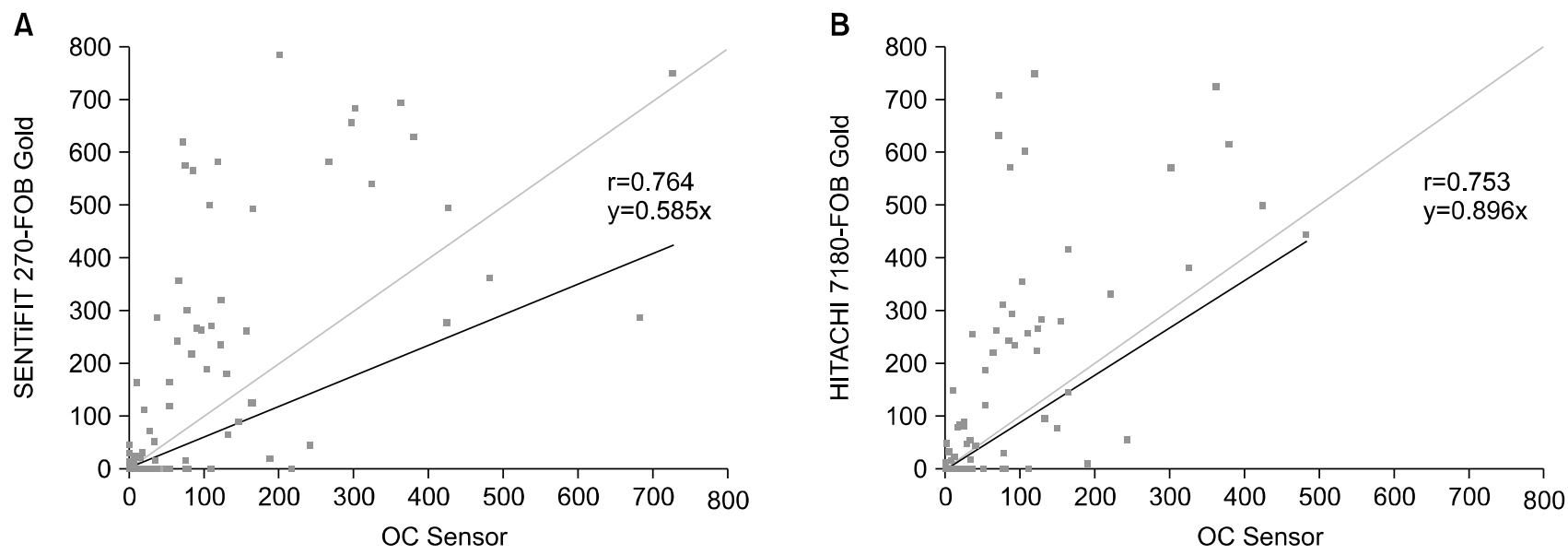

Fig. 2. Quantitative results of SENTiFIT 270-FOB Gold (A) and HITACHI 7180-FOB Gold (B) comparing with those of OC-Sensor PLEDIA. Black lines indicate Passing-Bablock fit lines, and grey lines indicate the identity lines.

따라서 총 일치율은 $93.9 \%$, kappa 값 0.832 로 우수한 상관성을 보여주었다(Table 2). SENTiFIT 270-FOB Gold와 HITACHI $7180-\mathrm{FOB}$ Gold의 결과를 비교하였을 때는, 총 362 개의 검체 중 HITACHI 7180-FOB Gold에서 양성으로 나온 검체는 91개였으 며, SENTiFIT 270-FOB Gold에서도 91개가 양성으로 $100 \%$ 일치 하고, HITACHI 7180-FOB Gold에서 음성으로 나온 검체 271개 중에 SENTiFIT 270-FOB Gold의 1개를 제외한 270개가 음성으로 나와 일치율이 $99.6 \%$ 였다.

평가장비 또는 비교장비에서 직선성을 검증한 범위를 벗어 난 결과를 보인 검체를 제외한 308 개의 측정 결과로 정량값의 상관성을 평가하였을 때, SENTiFIT 270-FOB Gold와 OC-Sensor (Eiken chemical Co.)의 결과값 간의 상관계수(r)는 0.764 였으며, Passing-Bablock 회귀분석 결과 회귀방정식은 $\mathrm{y}=0.585 \mathrm{x}$ 였다. HITACHI 7180-FOB Gold와 OC-Sensor (Eiken chemical Co.)의 결과값 간의 상관계수(r)는 0.753 이었으며, 회 귀방정식은 $\mathrm{y}=0.896 \mathrm{x}$ 였다(Fig. 2).

\section{DISCUSSION}

대장암의 조기 발견은 환자의 생존율을 높일 수 있음이 보고 되고 있으므로, 선별검사의 중요성이 높아지고 있다. 대변잠혈
검사는 대장암의 조기진단에 주로 사용되는 검사로 환자의 진 단 병기를 앞당기고, 사망률의 감소가 증명된 검사이다[6,14]. 본 연구에서는 대변잠혈검사 전용장비인 SENTiFIT 270-FOB Gold 시약을 이용한 검사능에 대해 평가하였으며, 임상검사실 의 범용장비인 HITACHI 7180 (Hitachi Ltd.)을 이용한 검사능 에 대하여도 평가하였다.

SENTiFIT 270-FOB Gold의 총 정밀도는 저농도, 고농도에 서 각각 $4.94 \%, 2.54 \%$ 로 우수한 결과를 보였으며, HITACHI $7180-\mathrm{FOB}$ Gold에서도 $4.6 \%, 2.09 \%$ 의 우수한 결과를 보여주었 다. 범용장비를 이용하였을 때 변이계수가 조금 더 낮았으며, 두 장비 모두에서 저농도가 고농도보다 조금 더 높은 편이나 변이계수가 $10 \%$ 이하였다. 기존에 보고된 SENTiFIT 270 (Sentinel diagnostics)의 분석능 평가에서 일괄검사 내 정밀도 와 일괄검사 간 정밀도는 각각 1.7-5.1\%와 3.8-6.2\%로 본 연구 결과와 유사한 결과를 보여주었다[10]. Kim 등[15]에 의하면, $\mathrm{OC}-\mathrm{Sensor} \mathrm{NEO}$ 의 정밀도는 일괄검사 내, 일괄검사 간 변이계 수는 저농도, 고농도에서 각각 $7.8 \%$ 와 $8.8 \%, 3.5 \%$ 와 $4.5 \%$ 로, 고농도에서보다 저농도에서 조금 더 높았으며, SENTiFIT 270-FOB Gold의 정밀도와 유사한 변이계수를 보여주었다. 국 외에서 널리 사용되는 장비인 HM-JACKarc (Kyowa Medex Co. Ltd, Japan)의 성능평가에서도 총 정밀도는 $7.1 \%$ 와 $3.8 \%$ 로 
본 연구와 유사한 결과를 보여주었다[16].

직선성 평가에서, 직선성 검증 범위는 SENTiFIT 270 (Sentinel diagnostics) 및 HITACHI 7180 (Hitachi Ltd.)에서 각 각 0.5-776.0 ng/mL, 0-1,132.5 ng/mL로, 보고범위인 0-800 $\mathrm{ng} / \mathrm{mL}$ 을 대부분 포함하였으며, 다중회귀평가에 의한 결정계수 는 SENTITIF 270-FOB Gold 및 HITACHI 7180-FOB Gold 모 두에서 0.99 이상이었고, 직선성 평가 회귀방정식 역시 1차 함 수로 우수한 직선성을 보여주었다.

검사 간 일치도 평가에서, SENTiFIT 270-FOB Gold와 OC-Sensor (Eiken chemical Co.), HITACHI 7180-FOB Gold와 OC-Sensor (Eiken chemical Co.)의 결과를 각각 비교하였을 때, 양성/음성 일치율은 각각 93.6\% (339/362), 93.9\% (340/362)였 다. SENTiFIT 270-FOB Gold와 HITACHI 7180-FOB Gold 간 의 결과 일치율은 $99.3 \%$ (361/362)였다. 측정가능 범위 내의 결 과를 이용한 정량값 간의 비교에서, OC-Sensor (Eiken chemical Co.)와 SENTiFIT 270-FOB Gold 간의 상관 계수는 0.762였으 며, OC-Sensor (Eiken chemical Co.)와 HITACHI 7180-FOB gold의 상관계수는 0.754 로 장비 간 결과에서 차이를 보였으며, Passing-Bablock 회귀방정식을 구하였을 때, 기울기가 1 미만으 로, FOB Gold 시약에 의한 측정값이 OC-Sensor (Eiken chemical Co.)에 비해 높은 값을 보였다. 기존에 HM-JACKarc을 평 가한 논문에 따르면 총 200 검체 중 198 검체(99.0\%)에서 일치 했고 2 검체만이 장비 간 불일치를 보였다[16]. OC-Sensor PLEDIA와 NS-Prime을 평가한 논문에서는 두 검사 간 양성과 음성 판독의 불일치가 3 검체에 불과하였고, 2검체는 PLEDIA 에서 양성이었고 1 개는 NS-Prime에서 양성으로 판독되었다 [17]. 불일치의 원인으로, 시약에 포함된 사람 헤모글로빈 항체 의 항원결정기가 상이할 수 있기 때문이다. 또한 OC-Sensor (Eiken chemical Co.)의 경우 산란도를 측정하는 반면에 SENTIFiT 270 (Sentinel diagnostics)의 경우 흡광도를 측정하 여 헤모글로빈의 농도를 측정하므로, 측정방법의 차이에 의해 결과의 차이를 보일 수 있을 것이다. 또한, 매우 소량의 대변 검체를 이용하기 때문에 많은 양의 변 검체가 채취된 경우, 대 변 검체가 균일하지 않고 채취부위나 검체의 성상에 따라 포함 되어 있는 혈액의 양이 다르기 때문에 다른 결과가 나올 수 있 을 것으로 판단된다. 다양한 대변잠혈검사 기기의 결과값에 대 한 표준화가 시도되었으며[18], “ $\mu \mathrm{g} \mathrm{Hb} / \mathrm{g}$ feces”로 표준화하는 것이 제시되었지만, 과거의 연구에서 장비 간의 정량값의 차이 가 커, 표준화에 어려움이 있었음이 보고된 바 있다[19].

SENTIFiT 270 (Sentinel diagnostics)의 시약인 FOB Gold는 검사실 범용장비에 적용이 가능하다. 대변잠혈검사는 임상검 사실에서 필수적인 검사이나, 중소 규모의 병원에서는 전용장 비를 사용하는 것에 어려움이 있어 도입이 쉽지 않다. FOB Gold 시약은 범용장비인 HITACHI 7180 (Hitachi Ltd.)으로 평 가하였을 때도 우수한 정밀도, 직선성 및 상관성을 보여주었다.
따라서 대변잠혈검사 건수가 적은 2차병원에서 그 유용성이 있 을 것으로 판단된다.

결론적으로 SENTiFIT 270-FOB Gold는 정밀도, 직선성 및 이월률의 검사능 평가에서 모두 우수한 결과를 보였고, 기존 장비인 OC-Sensor (Eiken chemical Co.)와도 우수한 상관성을 보였다. 또한, 범용장비인 HITACHI 7180-FOB Gold에서도 우 수한 성능을 보여주어 다양한 규모의 병원에서 사용할 수 있을 것이다.

\section{REFERENCES}

1. Jung KW, Won YJ, Oh CM, Kong HJ, Lee DH, Lee KH. Cancer statistics in Korea: incidence, mortality, survival, and prevalence in 2014. Cancer Res Treat 2017;49:292-305.

2. Jung KW, Park S, Kong HJ, Won YJ, Lee JY, Park EC, et al. Cancer statistics in Korea: incidence, mortality, survival, and prevalence in 2008. Cancer Res Treat 2011;43:1-11.

3. Haggar FA and Boushey RP. Colorectal cancer epidemiology: incidence, mortality, survival, and risk factors. Clin Colon Rectal Surg 2009;22:191-7.

4. National Cancer Center. Recommendation for screening of colorectal cancer. https://www.cancer.go.kr/docview/preview.do?uuid= af160571-788e-49ac-ae87-ab787ad2f97e.pdf [Online] (last visited on 26 Nov 2018).

5. Kronborg O, Fenger C, Olsen J, Jørgensen OD, Søndergaard O. Randomised study of screening for colorectal cancer with faecal-occult-blood test. Lancet 1996;348:1467-71.

6. Lauby-Secretan B, Vilahur N, Bianchini F, Guha N, Straif K; International Agency for Research on Cancer Handbook Working Group. The IARC perspective on colorectal cancer screening. N Engl J Med 2018;378:1734-40.

7. Park DI, Ryu S, Kim YH, Lee SH, Lee CK, Eun CS, et al. Comparison of guaiac-based and quantitative immunochemical fecal occult blood testing in a population at average risk undergoing colorectal cancer screening. Am J Gastroenterol 2010;105: 2017-25.

8. van Rossum LG, van Rijn AF, Laheij RJ, van Oijen MG, Fockens $\mathrm{P}$, van Krieken $\mathrm{HH}$, et al. Random comparison of guaiac and immunochemical fecal occult blood tests for colorectal cancer in a screening population. Gastroenterology 2008;135:82-90.

9. Jeon CH, Lee AJ, Kim SG, Suh HS, Bae YC. Annual report on the external quality assessment scheme for urinalysis and faecal occult blood testing in Korea (2016). J Lab Med Qual Assur 2017;39:117-23.

10. Auge JM, Rodriguez C, Espanyol O, Rivero L, Sandalinas S, Grau J, et al. An evaluation of the SENTiFIT 270 analyser for quantitation of faecal haemoglobin in the investigation of patients with suspected colorectal cancer. Clin Chem Lab Med 2018;56: 625-33.

11. CLSI. User verification of precision and estimation of bias; approved guideline. CLSI document EP15-A3. Wayne, PA: Clinical and Laboratory Standards Institute; 2014.

12. CLSI. Evaluation of the linearity of quantitative measurement procedures: a statistical approach; approved guideline. CLSI document EP06-A. Wayne, PA: Clinical and Laboratory Standards Institute; 2003.

13. CLSI. Method comparison and bias estimation using patient 
samples; approved guideline. CLSI document EP9-A2. Wayne, PA: Clinical and Laboratory Standards Institute; 2002.

14. Mandel JS, Bond JH, Church TR, Snover DC, Bradley GM, Schuman LM, et al. Reducing mortality from colorectal cancer by screening for fecal occult blood. Minnesota Colon Cancer Control Study. N Engl J Med 1993;328:1365-71.

15. Kim JH, Chung HJ, Yoon NS, Pyo YJ, Bae HG, Kim MN. Evaluation of the OC-SENSOR neo system for testing fecal occult blood. Korean J Lab Med 2007;27:210-5.

16. Park Y, Choi Q, Kwon GC, Koo SH. Performance evaluation of the HM-JACKarc analyser for fecal occult blood test. J Lab Med
Qual Assur 2016;38:137-42.

17. Ahn A, Kim J, Ko YJ, Sung H, Kim MN. Performance evaluation of two automated quantitative fecal occult blood tests. Lab Med Online 2016;6:233-9.

18. Fraser CG, Allison JE, Halloran SP, Young GP. A proposal to standardize reporting units for fecal immunochemical tests for hemoglobin. J Natl Cancer Inst 2012;104:810-4.

19. Grobbee EJ, van der Vlugt M, van Vuuren AJ, Stroobants AK, Mundt MW, Spijker WJ, et al. A randomised comparison of two faecal immunochemical tests in population-based colorectal cancer screening. Gut 2017;66:1975-82.

=국문초록=

\section{대변잠혈검사 자동화 장비인 SENTiFIT 270의 분석능 및 FOB Gold 시약의 분석능 평가}

${ }^{1}$ 연세대학교 의과대학 진단검사의학교실 및 세균내성연구소, ${ }^{2}$ 상지대학교 일반대학원 보건과학대학 임상병리학과 강다영 ${ }^{1,2}$, 김도균 $^{1}$, 김건한 $^{1}$, 장인호 $^{2}$, 정석훈 $^{1}$

배경: 대변잠혈검사는 대장암 진단을 위한 검사로 많이 사용되어 왔다. SENTiFIT 270 (Eiken chemical Co., Japan)은 FOB Gold 시약을 사용한 면역화학적 방법으로 대변잠혈검사를 시행한다. 우리는 대장암에 대한 1차 선별 검사로 널리 사용 되는 대변잠혈검사인 FOB Gold 시약을 이용한 SENTiTIF 270의 성능을 평가하였으며, 추가적으로 검사실 범용장비인 HITACHI 7180 (Hitachi Ltd., Japan)을 이용하여 FOB Gold의 분석능을 평가하였다.

방법: SENTiFIT 270의 정밀도와 직선성은 해당 CLSI 가이드라인에 따라 평가되었다. SENTiFIT 270-FOB Gold와 HITACHI 7180-FOB Gold의 결과를 OC-Sensor (Eiken chemical Co., Japan)의 결과와 비교하여 일치도를 평가하였다. 결과: 정밀도 평가에서, SENTiFIT 270-FOB Gold의 총 정밀도는 고농도 및 저농도에서 각각 $4.94 \%, 2.54 \%$ 로 좋았다. HITACHI 7180-FOB Gold는 고농도 및 저농도에서 각각 4.60\%, 2.09\%의 우수한 정밀도를 보였다. 직선성 또한 SENTiFIT 270-FOB Gold 및 HITACHI 7180-FOB Gold에서 각각 상관계수 0.9987, 0.9986으로 측정가능범위에서 검증되었다. OC-Sensor와 비교하였을 때, SENTiFIT 270-FOB Gold는 kappa 값 0.830과 일치율 93.6\%로 우수한 일치도를 보여주었고, HITACHI 7180-FOB Gold는 kappa 값 0.832 와 일치율 $93.9 \%$ 로 높은 일치도를 보여주었다.

결론: SENTiFIT 270-FOB Gold 및 HITACHI 7180-FOB Gold는 우수한 분석능을 보여 다양한 규모의 임상검사실에서 사 용 가능할 것으로 판단된다. [Ann Clin Microbiol 2019;22:29-34]

교신저자 : 김도균, 06273 , 서울시 강남구 언주로 211

연세대학교 의과대학 강남세브란스병원 진단검사의학과 및 세균내성연구소

Tel: 02-2019-2776, Fax: 02-2057-8926

E-mail: kyunsky@yuhs.ac 